\begin{tabular}{|c|l|}
\hline Title & Ripple formation on a nickel electrode during a glow discharge in a solution \\
\hline Author(s) & Saito, Genki; Hosokai, Sou; Tsubota, Masakatsu; A kiyama, Tomohiro \\
\hline Citation & $\begin{array}{l}\text { A pplied Physics Letters, 100(18), 181601 } \\
\text { https://doi.org/10.1063/4709491 }\end{array}$ \\
\hline Issue Date & 2012-04 30 \\
\hline Doc URL & http://hdl.handle.net/2115/49282 \\
\hline Rights & $\begin{array}{l}\text { Copyright 2012 A merican Institute of Physics. This article may be downloaded for personal use only. A ny other use } \\
\text { requires prior permission of the author and the A merican Institute of Physics. The following article appeared in A ppl. } \\
\text { Phys. Lett. 100, 181601 (2012) and may be found at https://dx.doi.org/10.1063/1.4709491 }\end{array}$ \\
\hline Type & article \\
\hline File Information & APL100-18_181601.pdf \\
\hline
\end{tabular}

Instructions for use 


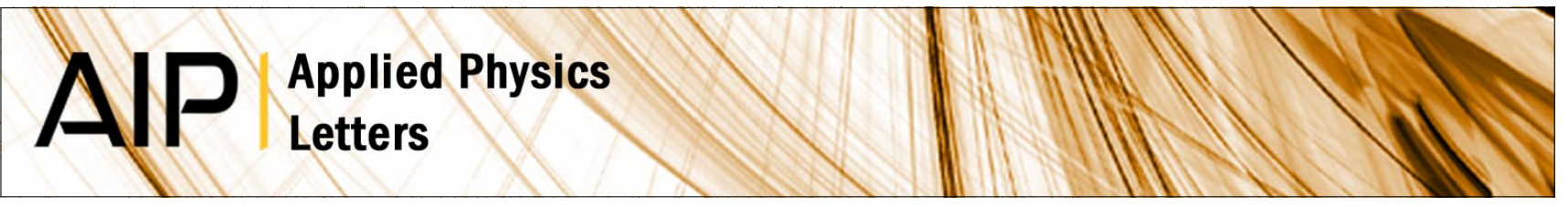

Ripple formation on a nickel electrode during a glow discharge in a solution

Genki Saito, Sou Hosokai, Masakatsu Tsubota, and Tomohiro Akiyama

Citation: Appl. Phys. Lett. 100, 181601 (2012); doi: 10.1063/1.4709491

View online: http://dx.doi.org/10.1063/1.4709491

View Table of Contents: http://apl.aip.org/resource/1/APPLAB/v100/i18

Published by the American Institute of Physics.

\section{Related Articles}

Designing a miniaturised heated stage for in situ optical measurements of solid oxide fuel cell electrode surfaces, and probing the oxidation of solid oxide fuel cell anodes using in situ Raman spectroscopy

Rev. Sci. Instrum. 83, 053707 (2012)

Efficiency enhancement for bulk heterojunction photovoltaic cells via incorporation of alcohol soluble conjugated polymer interlayer

Appl. Phys. Lett. 100, 203304 (2012)

Efficiency enhancement for bulk heterojunction photovoltaic cells via incorporation of alcohol soluble conjugated polymer interlayer

APL: Org. Electron. Photonics 5, 111 (2012)

Red-green-blue polymer light-emitting diode pixels printed by optimized laser-induced forward transfer Appl. Phys. Lett. 100, 203303 (2012)

Red-green-blue polymer light-emitting diode pixels printed by optimized laser-induced forward transfer APL: Org. Electron. Photonics 5, 110 (2012)

\section{Additional information on Appl. Phys. Lett.}

Journal Homepage: http://apl.aip.org/

Journal Information: http://apl.aip.org/about/about_the_journal

Top downloads: http://apl.aip.org/features/most_downloaded

Information for Authors: http://apl.aip.org/authors

\section{ADVERTISEMENT}
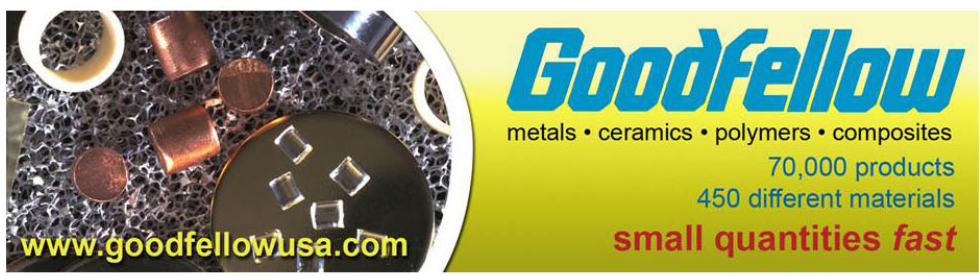


\title{
Ripple formation on a nickel electrode during a glow discharge in a solution
}

\author{
Genki Saito, Sou Hosokai, Masakatsu Tsubota, and Tomohiro Akiyama ${ }^{\text {a) }}$ \\ Center for Advanced Research of Energy and Materials, Hokkaido University, Sapporo 060-8628, Japan
}

(Received 28 February 2012; accepted 16 April 2012; published online 30 April 2012)

\begin{abstract}
We investigated ripple formation on a nickel electrode during a glow discharge in a solution. A nickel wire was partially melted to produce nanoparticles during glow discharge electrolysis. When the electrolysis time was over $30 \mathrm{~min}$, a ripple pattern was formed on the electrode surface, and particle size increased. In this study, we investigated the relationship between the ripple formation and crystal orientation of the electrode. As a result, the ripple patterns were formed on all planes, except (111)- and (100)-oriented planes; their direction was [001]. (c) 2012 American Institute of Physics. [http://dx.doi.org/10.1063/1.4709491]
\end{abstract}

The fabrication of regular structures has been used in many technological applications in a variety of fields. Among these structures, the formation of ripple structures and laser-induced periodic surface structures (LIPSSs) has attracted much research interest in recent years, both in terms of understanding its underlying physical mechanism and for potential applications such as acting as a template for quantum dot formation, ${ }^{1}$ fabrication of nanowires, ${ }^{2}$ and depthprofiling analysis. ${ }^{3}$ To obtain the rippled structure, ion-beam sputtering $^{4-7}$ and laser irradiation ${ }^{8,9}$ have been employed.

When a high direct-current voltage is applied to a conductive electrode in a solution, a plasma layer is generated in the interface between the electrode and the solution. Under this condition, the electrode is referred to as "a glow discharge electrode" by Hickling and Ingram, ${ }^{10}$ who reviewed the light emission from this electrode. A solution plasma system using glow discharge electrolysis has been applied to the synthesis of nanoparticles. ${ }^{11-16}$ However, the electrode surface during a nanoparticles synthesis has not been investigated deeply.

In this study, we discovered that a rippled structure was formed on the glow discharge electrode during a nanoparticles synthesis. We have investigated the dependence of the ripple formation on the crystal orientation of the electrode. The experimental setup consisted of two electrodes in a glass cell. The cathode was a nickel wire with a diameter of $1.0 \mathrm{~mm}$; the counter electrode was a platinum wire. A $0.1 \mathrm{M} \mathrm{NaOH}$ solution was used as the electrolyte. A plasma layer of a glow discharge was generated around the cathode and was maintained by applying $140 \mathrm{~V}$ (using a direct-current power supply). The electrolysis time was changed over the range of 1-360 min. The electrode was characterized using a scanning electron microscope (SEM). The volume mean diameter of the nanoparticles was measured using a transmission electron microscope (TEM). The electrode was characterized using an electron backscatter diffraction (EBSD) technique. For the EBSD analysis, the surface of the electrode wire was mechanically polished using a rotary sander before electrolysis.

When the voltage was $50 \mathrm{~V}$ or less, the electrolysis of water occurred, and the current increased with increasing

\footnotetext{
${ }^{\text {a) }}$ Author to whom correspondence should be addressed. Electronic mail: takiyama@eng.hokudai.ac.jp.
}

voltage. Because the electrical resistance heating of the solution was concentrated in the region of the solution surrounding the cathode, the solution near the cathode heated to the boiling point and a gas layer, containing hydrogen gas and steam, was generated. Once the gas layer has been generated near the cathode's surface, the current cannot increase any further and, instead, decreases, because the cathode and the solution are no longer in contact. If the voltage is sufficiently high, the gas layer forms a glow discharge plasma. When the voltage is over $120 \mathrm{~V}$, glow discharge occurs. The intensity of the light emission increases with increasing voltage.

Figure 1 shows the SEM images of the nickel electrode after electrolysis for different electrolysis times. The electrolysis time was varied from 1 to $360 \mathrm{~min}$. When the electrolysis time was less than $5 \mathrm{~min}$, a particle-coated surface was generated on the surface of the electrode [Figs. 1(a) and 1(b)]. With more than $30 \mathrm{~min}$ electrolysis time, ripple patterns were formed on the electrode's surface [Figs. 1(c) and 1(d)]. The spacing of these patterns increased with increasing time; $1.4 \mu \mathrm{m}$ at $30 \mathrm{~min}$ and $1.9 \mu \mathrm{m}$ at $360 \mathrm{~min}$. From the size distribution of the produced nanoparticles shown in Fig. 2, the particle size increased with increasing electrolysis time. The modal diameter did not change significantly for different electrolysis times. The ratio of coarse particles with a diameter greater than $500 \mathrm{~nm}$ was increased from $5.7 \mathrm{wt} \%$ at $5 \mathrm{~min}$ to $29 \mathrm{wt} . \%$ at $360 \mathrm{~min}$. These results suggest that the particle-coated surface, much like the surface at $5 \mathrm{~min}$, continuously produced small particles. The rippled surface likely produced the coarse particles.

To investigate the ripple formation mechanism, the electrode surface after $30 \mathrm{~min}$ of electrolysis was characterized using an EBSD technique. Figure 3(a) shows a SEM image of the nickel electrode before electrolysis. The electrode surface was mechanically polished and marked, as shown in the right side of Fig. 3(a), to locate the same area after electrolysis. The electrode surface was quite smooth and defect free. Figure 3(b) shows an EBSD orientation map of the nickel electrode surface before electrolysis. The grains are colorcoded based on the crystal direction perpendicular to the measured surface plane (normal direction, ND). The black lines indicate grain boundaries. The inset shows a standard triangle of a partial inverse-pole figure. This inverse-polefigure indicates that the nickel electrode had a polycrystalline 

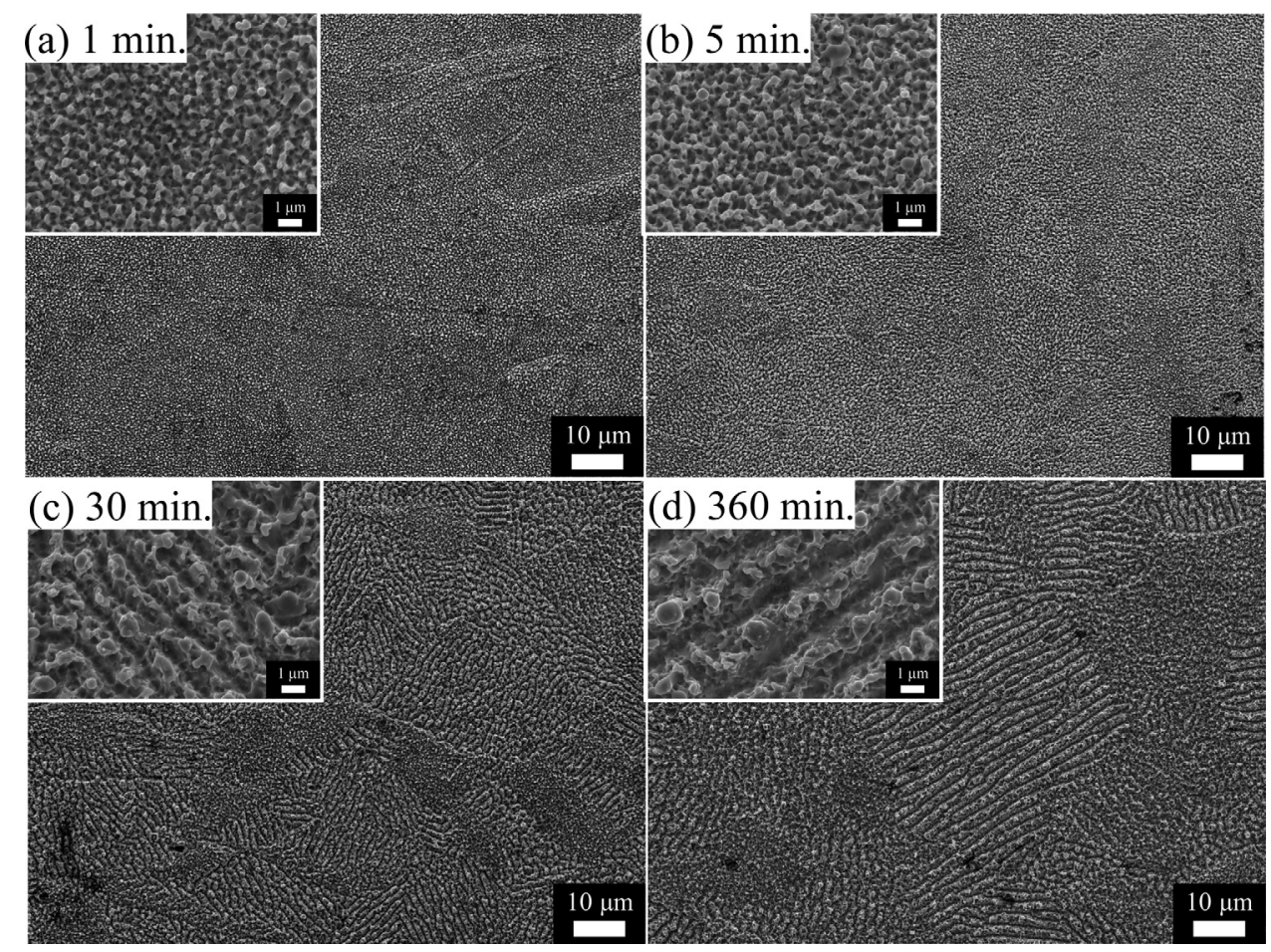

FIG. 1. SEM images of the electrode after experiments at different electrolysis time. The ripple patterns were formed over $30 \mathrm{~min}$. The spacing of these patterns became larger with time; $1.4 \mathrm{~mm}$ at $30 \mathrm{~min}$ and $1.9 \mathrm{~mm}$ at $360 \mathrm{~min}$. structure with the grain size of less than $50 \mu \mathrm{m}$ and that no crystal orientation anisotropy existed in the electrode. Figure 3(c) shows a SEM image of the nickel electrode after $30 \mathrm{~min}$ of electrolysis. We observed both a rippled surface and a particle-coated surface on the electrode. Regions with the same surface pattern are enclosed by black lines. It is noteworthy that the surface patterns agreed well with the crystal grains. This result indicates that the surface pattern depended upon the crystal orientation of the electrode; the black lines in Fig. 3(c) correspond to the grain boundaries.

Figure 4 shows enlarged SEM images and EBSD maps corresponding to Area 1 to 4 in Fig. 3(c). The arrows over-

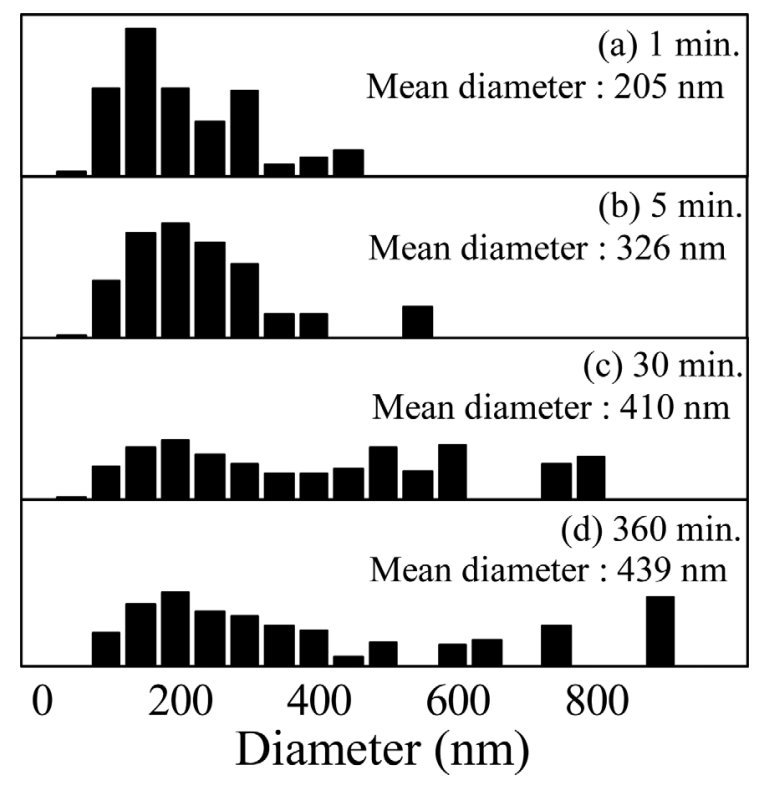

FIG. 2. Size distribution of the products at different electrolysis time. The volumetric mean diameter was evaluated by TEM images. laid on the SEM images show the direction of the ripple pattern. The cubes in the EBSD maps show the crystal lattice of a nickel sample at each grain. These cubes were drawn based on the calculation of the crystallographic tilt, as taken from the inverse-pole-figure. From these results, we know that the ripple patterns were formed on all planes except (111)- and (100)-oriented planes. The particle-coated surfaces were formed on the (111) plane and the (100) plane. The center grain in Area 2 is the (100) plane. The center of Area 4 contains a region in the (111) plane orientation. The direction of the ripple pattern depended upon the lattice orientation, as indicated by arrows in the EBSD maps; the lattice direction was [001].

Previous reports indicate that the nanoparticles are produced via two mechanisms in the solution plasma: local melting of an electrode because of the current concentration, which is induced by the electrothermal instability, ${ }^{13}$ and uniform sputtering in the form of a bombardment of charged particles in the plasma. ${ }^{12}$ The agglomeration of molten metals probably produced the particle-coated surface. However, ripple formation on the glow discharge electrode has not previously been reported. In the case of ion beam sputtering, ${ }^{4-7}$ $\mathrm{Xe}^{+}, \mathrm{Ar}^{+}, \mathrm{Kr}^{+}$, and $\mathrm{Ne}^{+}$ions have been used with an accelerating voltage of $1-60 \mathrm{kV}$. The incident angle and substrate temperature have an influence on the ripple formation. In the solution plasma, the main species in the plasma are $\mathrm{OH}^{-}$, $\mathrm{Na}^{+}, \mathrm{H}^{+}$, and ionized Ni. ${ }^{17}$ These ions seem to be too small to bombard the electrode surface. Additionally, the applied voltage of $140 \mathrm{~V}$ is relatively small, as compared to the ion beam irradiation. It is unlikely that ripple formation on the glow discharge electrode was induced by the ion sputtering process.

We are also considering the possibility of thermal etching, in which facets and grooves are generated on a surface via the evaporation, surface diffusion, and body diffusion of 


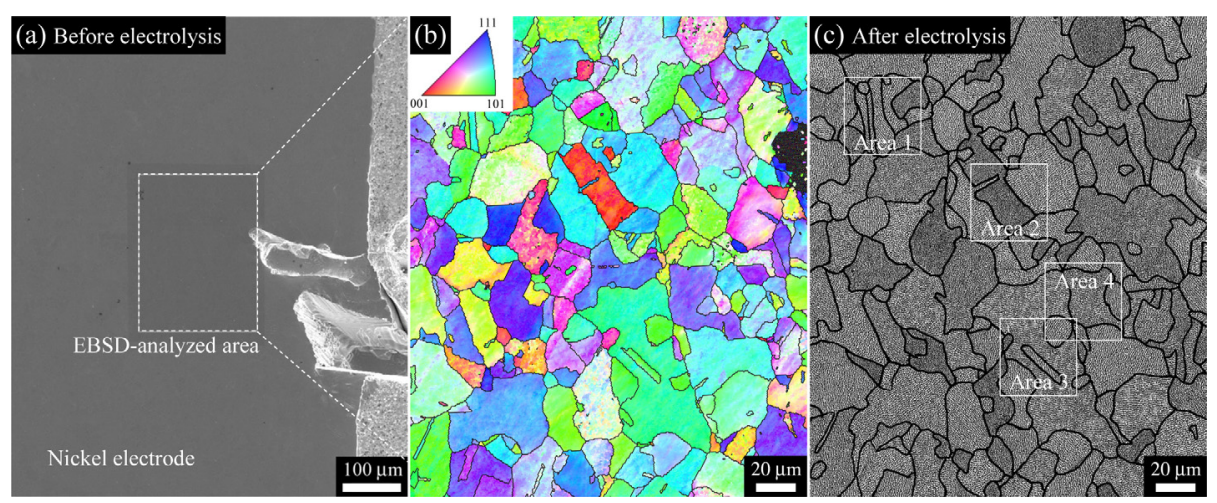

FIG. 3. (a) SEM images of the nickel electrode before electrolysis. (b) EBSD orientation map of the nickel electrode surface before electrolysis, in which the grains are color-coded by the crystal direction normal to the measured surface plane, and grain boundary is shown by a black solid line. (c) SEM image of the nickel electrode after electrolysis of $30 \mathrm{~min}$. The regions with a same surface pattern are enclosed by a black line.

an electrode. ${ }^{18}$ Faceting is a phenomenon in which a plane with a low surface energy grows on the sample surface under high temperature conditions. Grooves are generated at the
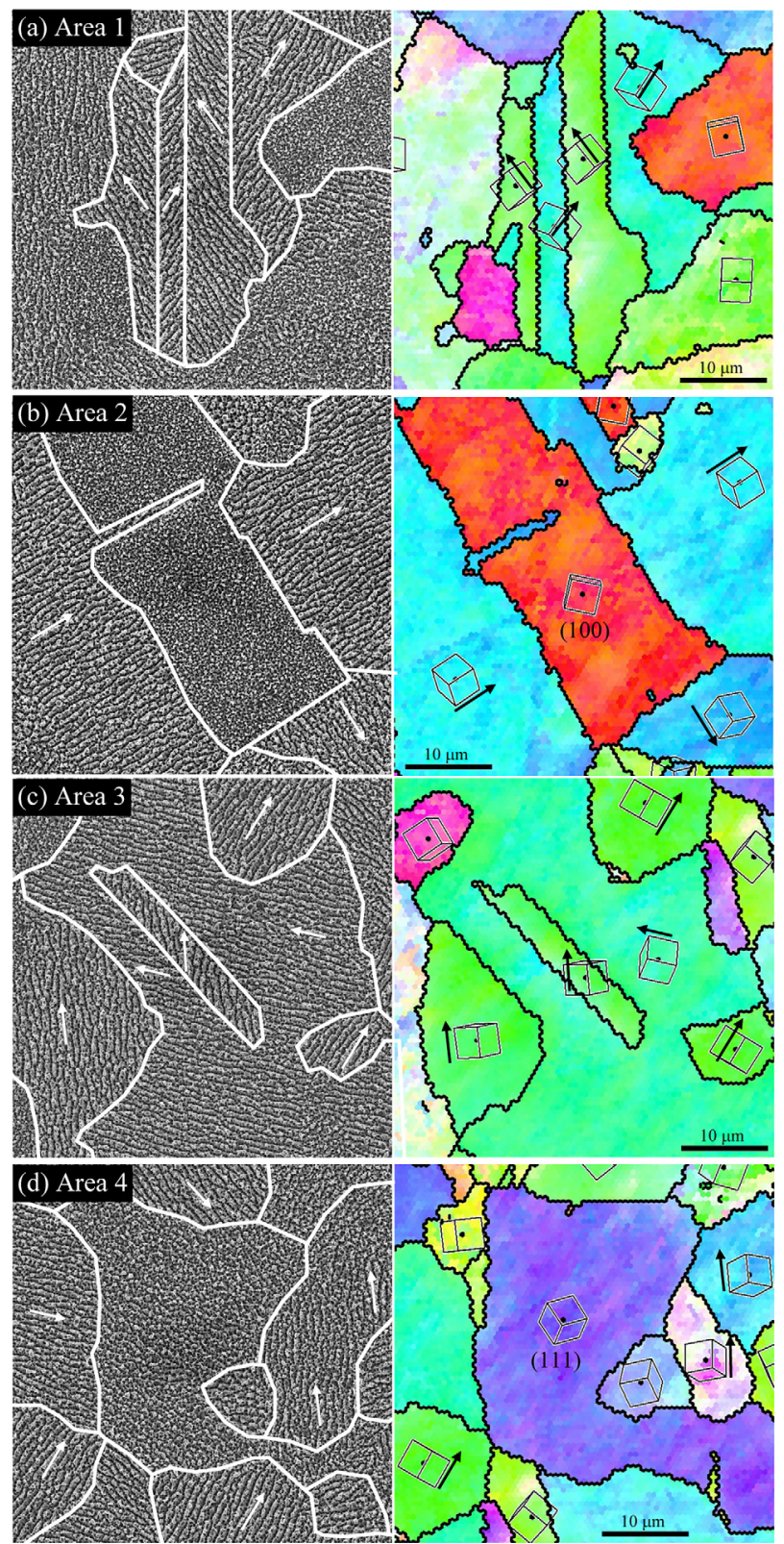

FIG. 4. Enlarged SEM images and EBSD maps corresponding to the Area 1 to 4 in Fig. 3(c). The arrows in SEM images show a direction of a ripple pattern. The cubes in EBSD maps show a crystal lattice of a face centered cubic (FCC) at each grain. The cubes are based on the calculation of the crystallographic tilt from inverse-pole-figure. grain boundaries. In certain cases, the thermally etched plane grows a rippled surface. ${ }^{18}$ In the case of a face-centeredcubic (FCC) like nickel, the surface energy increases in the following order; (111), (100), (110), and (210). According to the literature, the (111) and (100) facets have been observed on FCC surfaces. ${ }^{18,19}$ EBSD maps in Fig. 4 indicate that the direction of the ripple pattern is the [001] direction. If we denote the facet plane by $(\mathrm{k}, \mathrm{l}, \mathrm{m})$, the following relation will hold: $(1,1,0) \times(\mathrm{k}, 1, \mathrm{~m})=[0,0,1]$. We can calculate the facet planes: $\mathrm{k}-\mathrm{l}=1, \mathrm{~m}=0$. From these equations, the facet planes should be (100), (210), (310), etc. If the (111) facet is generated, the ripple pattern will be in the [110] direction. Generally, the facet plane is determined by the crystallographic tilting; the plane near the (111) plane generates the (111) facet. However, in the case of a glow discharge electrode, all facet planes probably consisted of the (100) plane. There is a possibility, that is, that the surface oxidation changed the surface stability so as to selectively stabilize the (100) plane.

In conclusion, the relationship between ripple formation and the crystal orientation of an electrode was investigated. When the electrolysis time was greater than $30 \mathrm{~min}$, the electrode surface was changed from a particle-coated surface into a rippled surface. The formation of the coarse particles from the rippled surface contributed to a net increase in particle size. EBSD maps indicated that the ripple patterns were formed on all planes except the (111)- and (100)-oriented planes. The direction of the ripple pattern was [001]. The ripple pattern was likely generated because of the thermal etching during the glow discharge in a solution. These results suggest that the particle size is controllable by changing the crystallographic face of an electrode. In the case of a nickel electrode, the (100)- and (111)-oriented planes will produce small particles.

${ }^{1}$ G. Li, J. Zhang, L. Yang, Y. Zhang, and L. Zhang, Scr. Mater. 44, 1945 (2001).

${ }^{2}$ J. Kim, B. Kahng, and A.-L. Barabasi, Appl. Phys. Lett. 81, 3654 (2002).

${ }^{3}$ S. Mp, Vacuum 36, 399 (1986).

${ }^{4}$ B. Ziberi, F. Frost, M. Tartz, H. Neumann, and B. Rauschenbach, Appl. Phys. Lett. 92, 063102 (2008).

${ }^{5}$ P. Karmakar and D. Ghose, Surf. Sci. 554, L101 (2004).

${ }^{6}$ T. K. Chini, D. P. Datta, and S. R. Bhattacharyya, J. Phys.: Condens. Matter 21, 224004 (2009).

${ }^{7}$ D. Sekiba, R. Moroni, G. Gonella, F. B. d. Mongeot, C. Boragno, L. Mattera, and U. Valbusa, Appl. Phys. Lett. 84, 762 (2004).

${ }^{8}$ Y. Yoshida, S. Watanabe, Y. Nishijima, K. Ueno, H. Misawa, and T. Kato, Nanotechnology 22, 375607 (2011).

${ }^{9}$ R. Wagner, J. Gottmann, A. Horn, and E. W. Kreutz, Appl. Surf. Sci. 252, 8576 (2006). 
${ }^{10}$ A. Hickling and M. Ingram, J. Electroanal. Chem. 8, 65 (1964).

${ }^{11}$ G. Saito, S. Hosokai, M. Tsubota, and T. Akiyama, Plasma Chem. Plasma Proc. 31, 719 (2011).

${ }^{12}$ K. Azumi, A. Kanada, M. Kawaguchi, and M. Seo, Hyomen Gijutsu 56, 938 (2005).

${ }^{13}$ Y. Toriyabe, S. Watanabe, S. Yatsu, T. Shibayama, and T. Mizuno, Appl. Phys. Lett. 91, 041501 (2007).

${ }^{14}$ G. Saito, S. Hosokai, and T. Akiyama, Mater. Chem. Phys. 130, 79 (2011).
${ }^{15}$ G. Saito, S. Hosokai, M. Tsubota, and T. Akiyama, J. Appl. Phys. 110, 023302 (2011).

${ }^{16}$ G. Saito, S. Hosokai, T. Akiyama, S. Yoshida, S. Yatsu, and S. Watanabe, J. Phys. Soc. Jpn 79, 083501 (2010).

${ }^{17}$ K. Azumi, T. Mizuno, T. Akimoto, and T. Ohmori, J. Electrochem. Soc. 146, 3374 (1999).

${ }^{18}$ G. E. Rhead and H. Mykura, Acta Metall. 10, 843 (1962).

${ }^{19}$ J. M. Blakely and H. Mykura, Acta Metall. 9, 595 (1961). 